\title{
Hepatoprotective effect of total flavonoids from Laggera alata against carbon tetrachloride-induced injury in primary cultured neonatal rat hepatocytes and in rats with hepatic damage
}

\author{
Yihang $\mathrm{Wu}^{1}{ }^{1}$, Fang $\mathrm{Wang}^{2}$, Qunxiong Zheng ${ }^{3}$, Longxi Lu ${ }^{4}$, Hongtian Yao ${ }^{5}$, Changxin \\ Zhou $^{1}$, Xiumei $\mathrm{Wu}^{1} \& \mathrm{Yu} \mathrm{Zhao}{ }^{1}$ \\ ${ }^{1}$ Department of Traditional Chinese Medicine and Natural Drug Research, College of Pharmaceutical Sci- \\ ences, Zhejiang University, Hangzhou 310031, China ${ }^{2}$ Hangzhou Huqingyutang Pharmaceutical Co., Ltd., \\ Hangzhou 310002, China; ${ }^{3}$ College of Food Science, Biotechnology \& Environmental Engineering, Zhejiang \\ Gongshang University, Hangzhou 310035, China; ${ }^{4}$ Zhejiang Provincial Center for Disease Prevention and \\ Control, Hangzhou 310009, China; ${ }^{5}$ Pathology Department, First Affiliated Hospital, ZheJiang University \\ College of Medicine, Hangzhou 310003, China
}

Received 13 December 2005; accepted 21 February 2006 (C) 2006 National Science Council, Taipei

Key words: antioxidative activity, carbon tetrachloride, flavonoids, hepatoprotective activity, Laggera alata

\section{Summary}

The hepatoprotective activities of total flavonoids of Laggera alata (TFLA) were evaluated by carbon tetrachloride $\left(\mathrm{CCl}_{4}\right)$-induced injury in primary cultured neonatal rat hepatocytes and in rats with hepatic damage. In vitro, TFLA at a concentration range of $1-100 \mu \mathrm{g} / \mathrm{ml}$ improved cell viability and inhibited cellular leakage of two enzymes, hepatocyte aspartate aminotransferase (AST) and alanine aminotransferase (ALT), caused by $\mathrm{CCl}_{4}$. In vivo, oral treatment with TFLA at doses of 50,100 , and $200 \mathrm{mg} / \mathrm{kg}$ significantly reduced the levels of AST, ALT, total protein, and albumin in serum and the hydroxyproline and sialic acid levels in liver. Histopathological examinations revealed that liver damage were improved when treated with TFLA. Meanwhile, 1,1-diphenyl-2-picrylhydrazyl (DPPH) and superoxide radicals scavenging activities of TFLA were also determinated. To understand the exact components of TFLA responsible for the hepatoprotective effect, nine flavonoid compounds were isolated and identified from TFLA. In conclusion, the present investigation was the first to verify the hepatoprotective effect of $L$. alata in vitro and in vivo. The hepatoprotective action of TFLA is likely related to its potent antioxidative and anti-inflammatory activity. Neutralizing reactive oxygen species by nonenzymatic mechanisms and enhancing the activity of original natural hepatic-antioxidant enzymes may be the main mechanisms of TFLA against $\mathrm{CCl}_{4}$-induced injury.

\section{Introduction}

The therapeutic benefits of traditional chinese medicines have been recognized for centuries. Although there is still lack of evidence for

*To whom correspondence should be addressed. Fax: + 86-5718781-7751; Tel.: +86-571-8723-0506; E-mail: yihangwu@ 126.com clarification of their typical mechanisms, unlike with Western medicine, it is still widely accepted by people from East Asia and beginning to be accepted by the rest of the world. Of the 20 species of the genus Laggera, distributing mainly in tropical Africa and Southeast Asia, L. alata and L. pterodonta are the only two found in China. Both are employed as folk medicines for the treatment of inflammatory disorders. The 
herb L. alata has attracted much attention in the last few decades because of its remarkable ability to cure some ailments associated with inflammation, especially hepatitis, arthritis, bronchitis and nephritis. However, most studies have focused on folk use and phytochemical work. On the other hand, no systematic bioactivity studies have been carried out on the folk medicine. Based on our previous work on the phytochemistry of this genus [1-8], we have studied the anti-inflammatory activity of total flavonoids of L. alata (TFLA) and confirmed the potent inhibitory effects of TFLA in acute and chronic models [9].

To further validate the remarkable curative effect of L. alata in hepatitis, in this paper we evaluated hepatoprotective effects of total flavonoids of $L$. alata (TFLA) by $\mathrm{CCl}_{4}$-induced injury in primary cultured neonatal rat hepatocytes and in rats with hepatic damage. Meanwhile, For clarifying the action mechanisms of TFLA, its DPPH and superoxide radicals scavenging activities were also evaluated. These data indicated that TFLA displays potent hepatoprotective and antioxidative activities in the models that we have employed.

\section{Materials and methods}

\section{Chemicals}

Carbon tetrachloride $\left(\mathrm{CCl}_{4}\right)$, insulin, dexamethasone, penicillin, streptomycin, dimethyl sulfoxide (DMSO), 3-(4,5-dimethylthiazol-2-yl)-2,5diphenyltetrazolium bromide (MTT), silibinin, quercine, 1,1-diphenyl-2-picrylhydrazyl radical (DPPH), phenazine methosulfate, nitroblue tetrazolium and $\beta$-nicotinamide adenine dinucleotide hydrogen (NADH, reduced form) were purchased from Sigma Chemical Co. (St Louis, MO, USA). Aspartate aminotransferase (AST) and alanine aminotransferase (ALT) diagnostic kits were also purchased from Sigma. Sialic acid (SA), hydroxyproline, total protein, and albumin detection kits were purchased from Nanjing Jiancheng Bioengineering Institute (China). Fetal bovine serum (FBS) and 1640 medium were purchased from Gibco-BRL (Grand Island, NY, USA). All other reagents were of the highest commercial grade available.

\section{Plant materials}

Entire plants of Laggera alata were collected from Tengchong County, Yunnan Province, China in August 2003 and identified by Professor Liurong Chen, Department of Traditional Chinese Medicine and Natural Drug Research, College of Pharmaceutical Sciences, Zhejiang University, China. A voucher specimen (no. ZY982003LA) was deposited in the herbarium of the College of Pharmaceutical Sciences, Zhejiang University, China.

\section{Preparation of TFLA}

The aerial parts of L. alata $(10 \mathrm{~kg})$ were dried in the shade, cut into segments with $0.5-2.0 \mathrm{~cm}$ in length, and extracted three times with $95 \%$ ethanol. The extracts were combined and concentrated under reduced pressure, yielding a dark-green tarry mass (836 g), which was dissolved in hot water. This solution was basified to $\mathrm{pH} 9-10$ with $5 \%$ sodium carbonate, followed by repeated extraction with chloroform to remove the lipophilic constituents. The remaining aqueous extract was acidified to $\mathrm{pH} 4$ using $1 \mathrm{~N}$ hydrochloric acid and then further partitioned with ethyl acetate. The ethyl acetate fraction was washed with water to $\mathrm{pH} 7$ and condensed under reduced pressure, which resulted in a dark-brown powder that reacted intensely with magnesium hydrochloric acid. This powder (165 g) is referred to as total flavonoids of L. alata (TFLA).

\section{Isolation and elucidation of active components from TFLA}

The TFLA (40 g) was subjected to silica gel column chromatography and then eluted with $\mathrm{CHCl}_{3}$ with increasing concentrations of $\mathrm{MeOH}$, affording six fractions. These fractions were repeatedly subjected to chromatography by passage through a Sephadex LH-20 column and elution with $\mathrm{CHCl}_{3}-\mathrm{MeOH}$ (from 1:0 to 0:1), followed by passage through an RP-18 gel column and final purification by passage through a silica gel column and elution with a gradient of benzene- $\mathrm{MeOH}$ (from 8:1 to 2:1). As a result, nine flavonoid compounds were identified as described previously [10-15]. Such as Artemitin (920 mg); Chrysosptertin B (1580 mg); Luteolin-3,3', $4^{\prime}$-trimethyl 
ether (412 mg); Casticin (31 mg); Quercetin-3,3'dimethyl ether (12 mg); Centaureidin (21 mg); $3^{\prime}, 4^{\prime}, 5$-Trihydroxyl-3,7-dimethoxyflavone (16 mg); 5-Hydroxy-3,3',4',7-tetramethoxyflavone (12 mg) and Quercetagetin-3,3',6-trimethylether (10 mg). Their structures are shown in Figure 1.

\section{Animals}

Male Sprague-Dawley rats weighing 180-220 g were bred in a standard animal house. The animals were kept in a room maintained at $22 \pm 2^{\circ} \mathrm{C}$ and at a relative humidity between $40 \%$ and $70 \%$. The animals had free access to food and water. The experimental protocol was approved by the Animal Ethics Committee of Zhejiang University, in accordance with the Guiding Principles in the Use of Animals in Toxicology, adopted by the Society of Toxicology (USA) in July 1989 and revised in March 1999.

\section{Isolation and culture of primary hepatocytes}

Neonatal rat primary hepatocytes were isolated from 3-day-old Sprague-Dawley rats according to the method of Anil Kumar et al. [16], with some modifications. The cell viability, as determined by Trypan blue exclusion assay, was over $90 \%$. The isolated hepatocytes were suspended in 1640 medium supplemented with $10 \%$ FBS, $100 \mathrm{U} / \mathrm{ml}$ penicillin, $100 \mathrm{U} / \mathrm{ml}$ streptomycin, $3 \mathrm{mM}$ glutamine, $0.16 \mathrm{U} / \mathrm{ml}$ insulin, and 9.6- $\mu \mathrm{g} / \mathrm{ml}$ dexamethasone, and then transferred to collagen-precoated 96-well culture plates at a density of approximately $5 \times 10^{5}$ cells $/ \mathrm{cm}^{2}$. After plating, the cells were incubated at $37{ }^{\circ} \mathrm{C}\left(95 \%\right.$ humidity, $\left.5 \% \mathrm{CO}_{2}\right)$. Hepatocyte attachment to the culture plate was completed 3 days after plating, and the medium was exchanged. Twelve hours later, the hepatocytes were treated with hepatotoxic agents and tested in the following assays.

\section{$\mathrm{CCl}_{4}$-induced primary hepatocyte injury}

Cellular cytotoxicity induced by TFLA treatment was measured using the MTT assay as follows: Hepatocytes were cultured in 1640 medium in the presence of $1-100 \mu \mathrm{g} / \mathrm{ml}$ TFLA for $48 \mathrm{~h}$, and then $10 \mu \mathrm{l}$ of MTT $(5 \mathrm{mg} / \mathrm{ml})$ was added to the cells in each well. After $4 \mathrm{~h}$ of culture, the medium was removed, and the blue formazan crystals that had formed were dissolved in DMSO. The optical

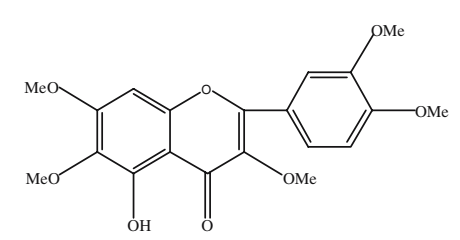

Artemitin<smiles>COc1cc(-c2oc3cc(O)c(O)c(O)c3c(=O)c2O)ccc1O</smiles>

Chrysosptertin B<smiles>COc1ccc(-c2oc3cc(C)cc(O)c3c(=O)c2O)cc1O</smiles>

Luteolin-3,3',4'-trimethyl ether<smiles>COc1ccc(-c2oc3cc(O)c(O)c(O)c3c(=O)c2O)cc1O</smiles><smiles>COc1cc2oc(-c3ccc(O)c(O)c3)c(O)c(=O)c2c(O)c1O</smiles>

Casticin

3',4',5-Trihydroxyl-3,7-dimethoxyflavone<smiles>Cc1cc(-c2oc3cc(O)cc(O)c3c(=O)c2O)ccc1O</smiles><smiles>COc1cc(O)c2c(=O)c(C)c(-c3ccc(OC)c(C)c3)oc2c1</smiles>

Quercetin-3,3'-dimethyl ether<smiles>COc1ccc(-c2oc3cc(O)c(O)c(O)c3c(=O)c2O)cc1O</smiles>

Centaureidin
5-Hydroxy-3,3',4',7-tetramethoxyflavone<smiles>COc1cc(-c2oc3cc(O)c(O)c(O)c3c(=O)c2O)ccc1O</smiles>

Quercetagein3,3',6-trimethyl ether

Figure 1. Chemical structure of nine flavonoid s identified from Laggera alata. 
density of formazan generated from MTT was measured at $570 \mathrm{~nm}$ using an ELX 800 universal microplate reader. At this wavelength, there was no interference from TFLA. Cell survival was defined as the amount of formazan production relative to that of cells not treated with hepatotoxic chemicals, expressed as a percentage.

Hepatotoxic agents were dissolved in the culture medium. TFLA and silibinin were dissolved in DMSO and then diluted with culture medium (final concentration of DMSO in medium $<0.1 \%$ ). After the hepatocytes had been incubated for $6 \mathrm{~h}$ with $8-\mathrm{mM} \mathrm{CCl}_{4}$, in the absence of TFLA, the medium was exchanged. The cells were then incubated for another $48 \mathrm{~h}$ in culture medium containing TFLA. Control experiments indicated that the vehicles used in this study did not influence the extent of cellular damage. The uniform attachment of the cells was confirmed at the beginning of each experiment. Silibinin was used as a reference drug for all in vitro studies.

\section{Evaluation of primary hepatocyte injury}

Hepatocyte injury was assessed by measuring the amount of AST and ALT leakage as well as cell viability. AST and ALT leakages into the medium were quantified using diagnostic kits for each enzyme. Viability was calculated as described above.

\section{$\mathrm{CCl}_{4}$-induced hepatic damage in rats}

Sixty rats were divided into two groups with 50 and 10 animals. Liver damage was induced in 50 rats by subcutaneous injection of $\mathrm{CCl}_{4}(0.5 \mathrm{ml} / \mathrm{kg}, 10 \%$ in olive oil) twice a week for 8 weeks. To enhance the hepatotoxicity, all animals were starved overnight after $\mathrm{CCl}_{4}$ treatment every time. The other 10 rats were not given $\mathrm{CCl}_{4}$ but normal saline as a control. After hepatic damage modes were induced for 8 weeks, the 50 rats with liver injury were randomly divided into five groups of 10 animals each. Group A, which served as the model control, received normal saline orally. Group B received silibinin $100 \mathrm{mg} / \mathrm{kg}$ orally. Groups C, D, and E received TFLA 50,100 , and $200 \mathrm{mg} / \mathrm{kg}$ orally once a day for 4 weeks, respectively. The doses and treatment periods of the silibinin and TFLA were determined by the results of the pretest. No apparent adverse effects were observed during the treatments. At $4 \mathrm{~h}$ after the last treatment of drug, blood samples were collected under light ether anesthesia by direct cardiac puncture, and the serum was separated by centrifugation at $5000 \mathrm{rpm}$ for $10 \mathrm{~min}$ for assay of AST, ALT, total protein, and albumin. Liver samples were rapidly removed, rinsed in cold saline, and homogenized for hydroxyproline and SA examination. The remaining liver was fixed in $10 \%$ neutral-buffered formalin for histopathological analysis.

\section{Biochemical analysis of liver damage in rats}

For biochemical determinations, serum samples were processed as described in the instructions provided for the diagnostic kits. The serum levels of ALT, AST, total protein, and albumin were determined using the ALT, AST, total protein, and albumin detection kits, respectively. The degree of hepatic fibrosis was evaluated by quantifying the hydroxyproline and SA contents in the liver. Liver samples were processed as described in the instructions provided for the test kits and measured using the hydroxyproline and SA detection kits, respectively.

\section{Histopathological examination of liver injury in rats}

For histopathological analysis, liver specimens fixed in $10 \%$ neutral-buffered formalin were embedded in paraffin, sliced 5 - $\mu \mathrm{m}$ thick, and stained with hematoxylin and eosin (HE). The pathological changes were assessed and photographed under an Olympus BX-51 microscope.

\section{DPPH radical scavenging activity assay}

According to the method of Tapia et al. [17], the quenching of free radicals by TFLA were assessed spectrophotometrically against the absorbance of the stable DPPH free radical. In brief, $250 \mu 1$ reaction mixtures contained $185 \mu \mathrm{l}$ methanol, 40 $\mu$ l DPPH solution $(0.4 \mathrm{mg} / \mathrm{ml})$ dissolved in methanol, and $25 \mu \mathrm{l}$ the test sample which were dissolved in dimethyl sulfoxide and diluted by methanol to the concentrations of 600,60 and 6 $\mu \mathrm{g} / \mathrm{ml}$. The methanolic solution of DPPH and quercine served as a negative and positive control, respectively. The absorbance was measured at $517 \mathrm{~nm}$ after the mixtures incubated at $37^{\circ} \mathrm{C}$ for $30 \mathrm{~min}$. The results were expressed with 
the $50 \%$ value of inhibition concentration $\mathrm{IC}_{50}(\mu \mathrm{g} / \mathrm{ml})$ and percent inhibition (\%) from the control.

\section{Superoxide anion radical scavenging activity assay}

The superoxide anion radicals scavenging effect of TFLA was assessed spectrophotometrically as reported previously with a slight modification [18]. Superoxide anions were generated in a nonenzymic phenazine methosulfate-NADH system by following the reduction of nitroblue tetrazolium. In this assay, the superoxide anion radicals were generated in $300 \mu \mathrm{l}$ of $16 \mathrm{mM}$ Tris- $\mathrm{HCl}$ buffer $\mathrm{pH} 8.0$ containing $78 \mu \mathrm{M}$ NADH, $50 \mu \mathrm{M}$ nitroblue tetrazolium, $5 \mu \mathrm{M}$ phenazine methosulfate, and the test samples at various concentrations. The colour reaction between the superoxide anion radicals and nitroblue tetazolium was monitored at $560 \mathrm{~nm}$ in a spectrophotometer after 5 min of the incubation at room temperature. Quercetin was used as the positive control. The $\mathrm{IC}_{50}(\mu \mathrm{g} / \mathrm{ml})$ value and percent inhibition (\%) were calculated from the control.

\section{Statistical analysis}

Values are expressed as mean \pm standard deviation and analyzed statistically by one-way analysis of variance (ANOVA) and Student' $t$-test. $p<0.05$ was chosen as the criterion for statistical significance. Statistical analyses were carried out using SPSS version 10.0 software.

\section{Results}

Protective effect of TFLA on $\mathrm{CCl}_{4}$-induced hepatocyt injury

The cytotoxicity of TFLA toward neonatal rat primary hepatocytes was tested. The result showed that TFLA concentrations of $1-100 \mu \mathrm{g} / \mathrm{ml}$ were not toxic to the cells. Cytotoxicity was induced in neonatal rat primary hepatocytes by exposure to $8 \mathrm{mM} \mathrm{CCl}_{4}$, and the cells were subsequently treated with TFLA. As shown in Table 1, TFLA, at concentrations of $1-100 \mu \mathrm{g} / \mathrm{ml}$, significantly reduced cellular leakage of AST and ALT and improved cell viability.

\section{Effects of TFLA on serum parameters of hepatic damage rats}

The effects of the oral treatment of TFLA on the serum AST, ALT, total protein, and albumin levels of hepatic-damaged rats are shown in Table 2. The serum AST and ALT levels of the $\mathrm{CCl}_{4}$-only group were elevated, whereas the total protein and albumin contents and $\mathrm{A} / \mathrm{G}$ values of this group were reduced, thus indicating that liver cell damage was significantly induced. Simultaneous treatment with TFLA significantly attenuated the $\mathrm{CCl}_{4}$-induced elevation of the AST and ALT levels, the decrease of the total protein and albumin contents, and the reduction of $\mathrm{A} / \mathrm{G}$ values. These data suggest that TFLA reduced the $\mathrm{CCl}_{4}$-induced hepatic damage. Silibinin, used as the reference drug, indicated a similar effect.

Table 1. Protective effect of total flavonoids of L. alata (TFLA) on $\mathrm{CCl}_{4}$-induced hepatocyte injury.

\begin{tabular}{|c|c|c|c|c|}
\hline Treatment & Concentration $(\mu \mathrm{g} / \mathrm{ml})$ & AST (IU/l) & ALT (IU/l) & Cell survival ( $\%$ of control) \\
\hline Control & - & $40.27 \pm 1.06^{* * *}$ & $22.34 \pm 1.01 * * *$ & $100 \pm 7 * * *$ \\
\hline $\mathrm{CCl}_{4}$ control & - & $82.35 \pm 2.07$ & $41.25 \pm 2.13$ & $11 \pm 1$ \\
\hline \multirow[t]{4}{*}{ Silibinin } & 100 & $68.29 \pm 2.17^{*}$ & $34.02 \pm 3.04^{*}$ & $16 \pm 1 * *$ \\
\hline & 50 & $75.41 \pm 5.08$ & $39.26 \pm 4.17$ & $12 \pm 1$ \\
\hline & 10 & $81.27 \pm 3.05$ & $41.91 \pm 4.59$ & $11 \pm 1$ \\
\hline & 1 & $84.29 \pm 2.57$ & $43.08 \pm 2.07$ & $9 \pm 1$ \\
\hline \multirow[t]{4}{*}{ TFLA } & 100 & $45.28 \pm 3.06^{* * *}$ & $24.19 \pm 1.04 * * *$ & $46 \pm 2 * * *$ \\
\hline & 50 & $47.69 \pm 2.03 * * *$ & $28.31 \pm 2.38^{* * *}$ & $35 \pm 2 * * *$ \\
\hline & 10 & $53.14 \pm 3.01^{* * *}$ & $31.23 \pm 2.01 * * *$ & $29 \pm 1 * * *$ \\
\hline & 1 & $70.21 \pm 4.12 *$ & $35.22 \pm 1.33^{* *}$ & $15 \pm 1 * *$ \\
\hline
\end{tabular}

TFLA, total flavonoids from Laggera alata; AST, aspartate aminotransferase; ALT, alanine.

Values are expressed as means \pm S.D. of six replicates.

${ }^{*} p<0.05,{ }^{* *} p<0.01$, and ${ }^{* * *} p<0.001$ compared with the $\mathrm{CCl}_{4}$ control. 
Table 2. Effects of total flavonoids of L. alata (TFLA) on serum AST, ALT, total protein, and albumin levels of hepatic-damaged rats.

\begin{tabular}{|c|c|c|c|c|c|c|}
\hline Groups & Dose $(\mathrm{mg} / \mathrm{kg})$ & AST (IU/l) & $\operatorname{ALT}(\mathrm{IU} / 1)$ & Total protein $(\mathrm{g} / \mathrm{l})$ & Albumin $(\mathrm{g} / \mathrm{l})$ & $\mathrm{A} / \mathrm{G}$ \\
\hline Control & - & $37.33 \pm 4.25^{* * *}$ & $36.67 \pm 6.17 * * *$ & $80.42 \pm 0.70^{* * *}$ & $44.17 \pm 1.21^{* * *}$ & $1.15 \pm 0.03^{* *}$ \\
\hline $\mathrm{CCl}_{4}$ control & - & $78.07 \pm 9.50$ & $119.47 \pm 18.31$ & $62.99 \pm 2.15$ & $28.12 \pm 1.56$ & $0.81 \pm 0.09$ \\
\hline Silibinin & 100 & $43.17 \pm 1.89 * * *$ & $56.43 \pm 7.97 * * *$ & $72.82 \pm 0.69 * * *$ & $38.59 \pm 0.35^{* * *}$ & $0.98 \pm 0.01^{*}$ \\
\hline \multirow[t]{3}{*}{ TFLA } & 50 & $58.68 \pm 1.48^{*}$ & $77.17 \pm 9.34 * *$ & $68.84 \pm 0.68^{*}$ & $33.51 \pm 0.25^{* *}$ & $0.98 \pm 0.08^{*}$ \\
\hline & 100 & $48.20 \pm 2.51 * * *$ & $57.37 \pm 6.57 * * *$ & $75.86 \pm 1.03 * * *$ & $38.05 \pm 1.71 * * *$ & $1.07 \pm 0.02 * *$ \\
\hline & 200 & $40.43 \pm 5.11^{* * *}$ & $50.07 \pm 7.13 * * *$ & $78.06 \pm 0.29 * * *$ & $40.79 \pm 0.44 * * *$ & $1.34 \pm 0.05^{* * *}$ \\
\hline
\end{tabular}

Values are expressed as mean \pm S.D. of 10 rats.

$*_{p}<0.05, * * p<0.01$, and $* * * p<0.001$ compared with the $\mathrm{CCl}_{4}$ control.

Effects of TFLA on liver hydroxyproline and SA contents of hepatic-damaged rats

The effects of TFLA on the degree of hepatic fibrosis in rats with $\mathrm{CCl}_{4}$-induced damage are shown in Table 3 . In the $\mathrm{CCl}_{4}$-only treatment group, the liver hydroxyproline and SA contents, two hepatic fibrosis parameters were increased, thereby indicating that liver fibrosis was induced. However, the oral treatment with TFLA improved markedly the $\mathrm{CCl}_{4}$-induced elevation of liver hydroxyproline and SA contents. Silibinin showed a similar effect. These results indicated that TFLA improved the $\mathrm{CCl}_{4}$-induced hepatic fibrosis.

Histopathological effects of TFLA on hepaticdamaged rats

No histological abnormalities were observed in control rats. The administration of only $\mathrm{CCl}_{4}$ for 8 weeks caused serious liver damage (hepatocyte necrosis and swelling, formation of vacuoles in cells, hepatocyte fat deposition, and fibrosis), which appeared in all animals of this group. Administration of different doses of TFLA resulted in significant recovery of hepatocytes in different sections of the liver. At a dose of $200 \mathrm{mg} /$ $\mathrm{kg}$, TFLA showed almost complete normalization of the tissues (Figure 2). These observations further supported the antihepatotoxic activity of TFLA.

\section{DPPH radical and superoxide anion radical scavenging activities of TFLA}

DPPH radical and superoxide anion radical scavenging activities of TFLA and quercetin were shown in Table 4. At a concentration range of 0.6$60 \mu \mathrm{g} / \mathrm{ml}$, TFLA exhibited the strong radical scavenging activity, while quercetin as reference drug also showed the similar effect.

\section{Discussion}

The whole plant of $L$. alata has been widely used for several centuries as a folk medicine to ameliorate hepatitis in China, whereas there have been no studies on the hepatoprotective effect of this plant. Therefore, in the present investigation, the

Table 3. Effects of total flavonoids of L. alata (TFLA) on liver hydroxyproline and SA contents of hepatic-damaged rats.

\begin{tabular}{lllc}
\hline Groups & Dose $(\mathrm{mg} / \mathrm{kg})$ & Sialic acid $(\mathrm{mmol} / \mathrm{l})$ & Hydroxyproline $(\mu \mathrm{g} / \mathrm{g}$ prot $)$ \\
\hline Control & - & $3.04 \pm 0.22^{* * *}$ & $7.54 \pm 0.64^{* * *}$ \\
$\mathrm{CCl}_{4}$ control & - & $6.11 \pm 0.11$ & $28.87 \pm 1.00$ \\
Silibinin & 100 & $5.48 \pm 0.39^{* *}$ & $12.33 \pm 1.00^{* * *}$ \\
TFLA & 50 & $5.75 \pm 0.40^{*}$ & $18.48 \pm 1.00^{* * *}$ \\
& 100 & $4.79 \pm 0.39^{* *}$ & $15.83 \pm 0.99^{* * *}$ \\
& 200 & $4.41 \pm 0.47^{* *}$ & $12.51 \pm 1.78^{* * *}$ \\
\hline
\end{tabular}

Values are expressed as mean \pm S.D. of 10 rats.

${ }^{*} p<0.05, * * p<0.01$, and ${ }^{* * *} p<0.001$ compared with the $\mathrm{CCl}_{4}$ control. 
Table 4. DPPH and superoxide radical scavenging activities of total flavonoids of L. alata (TFLA).

\begin{tabular}{|c|c|c|c|c|c|}
\hline \multirow[t]{2}{*}{ Treatment } & \multirow[t]{2}{*}{ Concentration $(\mu \mathrm{g} / \mathrm{ml})$} & \multicolumn{2}{|l|}{ DPPH radical } & \multicolumn{2}{|c|}{ Superoxide radical } \\
\hline & & Inhibition $(\%)$ & $\mathrm{IC}_{50}(\mu \mathrm{g} / \mathrm{m} 1)$ & Inhibition $(\%)$ & $\mathrm{IC}_{50}(\mu \mathrm{g} / \mathrm{m} 1)$ \\
\hline \multirow[t]{3}{*}{ Quercetin } & 60 & 93.36 & 2.24 & 84.24 & 10.77 \\
\hline & 6 & 85.21 & & 30.45 & \\
\hline & 0.6 & 16.24 & & 8.27 & \\
\hline \multirow[t]{3}{*}{ TFLA } & 60 & 85.15 & 4.43 & 70.27 & 20.37 \\
\hline & 6 & 74.75 & & 21.54 & \\
\hline & 0.6 & 11.16 & & 5.29 & \\
\hline
\end{tabular}

$\mathrm{IC}_{50}$, value of the $50 \%$ inhibition concentration; Inhibition $(\%)$, percent inhibition of means of six replicates from the control.

hepatoprotective effects of TFLA were studied using a $\mathrm{CCl}_{4}$-induced injury model in primary cultured neonatal rat hepatocytes and a $\mathrm{CCl}_{4^{-}}$ induced chronic hepatic damage model in rats.

Chemical injury was induced in the cells by the classical hepatotoxic agents $\mathrm{CCl}_{4}$ to evaluate the hepatoprotective effect of TFLA in vitro. Cellular leakage of AST and ALT and decreased cell viability were observed in the cultured hepatocytes in response to the chemical agent, which are conventional inducers of hepatocyte injury. The stabilization of AST, ALT, and cell viability provides a clear indication of the improved functional status of the cells. Therefore, these parameters were used to assess the effect of TFLA in preventing hepatocyte injury.

$\mathrm{CCl}_{4}$ is a widely used hepatotoxic agent that enhances the formation of free radicals, which cause lipid peroxidation of cellular and organelle membranes [19]. These changes are similar to those observed during cellular oxidative stress, which is considered to play a prominent role in the pathogenesis of many diseases, including liver injury [20]. In cells exposed to $\mathrm{CCl}_{4}$, subsequent treatment with TFLA reduced cellular leakage of AST and ALT and improved cell viability, thus demonstrating the protective effect of the flavonoids on chemically injured hepatocytes.

Based on in vitro results of TFLA against $\mathrm{CCl}_{4}$-induced hepatocyte injury, we further studied the protection afforded by TFLA against $\mathrm{CCl}_{4}$-induced hepatic damage in rats. In the whole animal model, the increased levels of AST and ALT, the decreased level of total protein and albumin, and the decrease in $\mathrm{A} / \mathrm{G}$ values are classical indicators of liver damage. The degree of hepatic fibrosis was evaluated by quantifying the collagen and SA contents in the liver. The total collagen content in the liver was determined by estimation of hydroxyproline, a characteristic amino acid in collagen. The results of biochemical tests proved the significant corrective effect of TFLA on the biochemical parameters of liver damage. Simultaneously, according to histopathological examinations, severe hepatic lesions induced by $\mathrm{CCl}_{4}$ were remarkably reduced by the administration of TFLA, in good agreement with the results of biochemical tests and in vitro research.

Oxidative stress is the state of imbalance between the level of antioxidant defence system and production of oxygen-derived species. Increased $\mathrm{O}_{2}$ concentration and production of oxygen-derived species such as superoxide radical $\left({ }^{\bullet} \mathrm{O}_{2}^{-}\right)$, hydroxyl radical $\left(\mathrm{OH}^{\bullet}\right)$ and hydrogen peroxide cause oxidative stress [21]. DPPH and superoxide radical scavenging activity assays indicated that TFLA and quercetin were capable of scavenging DPPH and superoxide radicals in a dose dependent manner, thus suggesting the ability of TFLA to ameliorate oxidative stress.

Free radicals alter the structural and functional integrity of cells by a variety of mechanisms, including lipid peroxidation, sulfhydryl oxidation, proteolysis and shearing of the nuclear material. Healthy cells can scavenge free radicals effectively by their defensive system (antioxidant effects). In brief, there is a dynamic relationship between reactive oxygen species and antioxidants in the human body. In some pathological conditions, such as cells suffering ischaemic insult, the sudden generation of reactive oxygen species can dramatically upset this balance with an increased demand on the antioxidant defence system. Natural 
antioxidants including superoxide dismutase, catalase and glutathione peroxidase are depleted accompanied by accumulation of reactive oxygen species. In such a situation, natural products can play an important role in two aspects: enhance the activity of original natural antioxidants and neutralize reactive oxygen species by nonenzymatic mechanisms [21].

Oxidative stress is considered to play a prominent causative role in many diseases including liver damage [22]. $\mathrm{CCl}_{4}$ is known to enhance the formation of free radicals through metabolism and to cause lipid peroxidation of cellular and organelle membranes as a primary pathogenic step subsequently [19]. These phenomena are similar to the oxidative stress occurring in cells and tissues. In addition, it is well-known that inflammation is a basic damage reaction and often occurs in processes of cell and tissue injury. In previous research, we showed that TFLA possesses potent antiinflammatory activity [9]. Therefore, the hepatoprotective actions of TFLA are likely a result of its potent antioxidative and anti-inflammatory activity. Since DPPH and superoxide radical scavenging activity assays are the antioxidate test in vitro. The ability of TFLA to scavenge free radicals could not still be fully moved to explain the hepatoprotection mechanisms of TFLA in primary cultured neonatal rat hepatocytes and in rats with hepatic damage. Moreover, whether TFLA enhancing the activity of original natural hepatic-antioxidant enzymes including superoxide dismutase, catalase, glutathione peroxidase and glutathione S-transferase still maintains unknown. Therefore, hepatoprotection of TFLA may be achieved by scavenging free radicals and enhancing the activity of original natural hepatic-antioxidant enzymes to ameliorate oxidate stess from chemical-induced injury.

Flavonoids are commonly found in plants and have been shown to display a remarkable spectrum of biological activities, such as hepatoprotective, anti-inflammatory and antiviral activities [23]. Flavonoids also display many antioxidant properties - they scavenge free radicals and prevent lipid peroxidation [24]. It has been reported that flavonoids and sesquiterpenoids are the main secondary metabolites of plants of the genus Laggera [1-8, 11, 25-34]. The results presented herein demonstrate the hepatoprotective effects of TFLA in primary rat hepatocytes against hepatotoxicant and in rats with hepatic damage. Therefore, our findings suggest that flavonoids are the major active compounds responsible for the biological activity of $L$. alata. To fully understand the exact components of TFLA responsible for the hepatoprotective effect, we isolated nine flavonoid compounds from TFLA (Figure 1). Of course, nine flavonoids identified from $L$. alata indicated only that TFLA contains these nine components. It does not mean that TFLA contains only these nine flavonoids because others flavonoids may not still be isolated. The amount of these nine flavonoids does not express their actual content in TFLA, because it may be as a result of the large amount loss in the course of isolation. The hepatoprotective and/or antioxidative effects of these components or their derived flavonoids have been demonstrated individually [35-40]. The detailed mechanism of hepatoprotective action and the interactions among the different components responsible for the hepatoprotective effect of TFLA need to be investigated further.

In conclusion, our current investigation verifies, for the first time, the hepatoprotective effect of L. alata in primary cultured neonatal rat hepatocytes and in rats with hepatic damage and identifies the chemical components responsible for the hepatoprotective potential of this plant. The hepatoprotective action of TFLA is likely related to its potent antioxidative and anti-inflammatory activity. Neutralizing reactive oxygen species by nonenzymatic mechanisms and enhancing the activity of original natural hepatic-antioxidant enzymes may be the main mechanisms of TFLA against $\mathrm{CCl}_{4}$-induced injury. These data provide a scientific explanation for the folkloric uses of L. alata in the treatment of hepatitis. Additional, more detailed studies are currently in progress.

\section{Acknowledgements}

This work was supported by a grant from a foundation of the Chinese Ministry of Education and Zhejiang University.

\section{References}

1. Xiao Y.C., Zheng Q.X., Zhang Q.J., Sun H.D., Guéritte F. and Zhao Y., Eudesmane derivatives from Laggera pterodonta. Fitoterapia 74: 459-463, 2003.

2. Zhao Y., Yue J.M., Lin Z.W., Ding J.K. and Sun H.D., Eudesmane sesquiterpenes from Laggera pterodonta. Phytochemistry 44: 459-464, 1997. 
3. Zhao Y., Yue J.M., Lin Z.W. and Sun H.D., Eleven new eudesmane derivatives from Laggera pterodonta. J. Nat. Prod. 60: 545-549, 1997.

4. Zhao Y., Yue J.M., Lin Z.W., Wang D.Z., Ding J.K. and Sun H.D., Five new eudesmane derivatives from Laggera pterodonta. Acta Botanica Yunnanica 19: 207-210, 1997.

5. Zheng Q.X., Xu Z.J., Sun X.F., Gueritte F., Cesario M., Sun H.D., Cheng C.H.K., Hao X.J., Zheng Q.X., Zhang Q.J., Sun H.D. and Zhao Y., Laggera pterodonta-a Yunnan herbal medicine. J. Zhejiang Univ. (Med. Sci.) 31: 406-409, 2002.

6. Zheng Q.X., Xu Z.J., Sun X.F., Gueritte F., Cesario M., Cheng C.H.K., Sun H.D. and Zhao Y., New eudesmane and eremophilane derivatives from Laggera alata. Chin. Chem. Lett. 14: 393-396, 2003.

7. Zheng Q.X., Xu Z.J., Sun X.F., Wei Y., Sun H.D., Christopher H.K. and Zhao Y., Eudesmane and megastigmane glucosides from Laggera alata. Phytochemistry 23: 835-839, 2003.

8. Zheng Q.X., Xu Z.J., Sun X.F., Gueritte F., Cesario M., Sun H.D, Cheng C.H.K., Hao X.J. and Zhao Y., Eudesmane derivatives and other sesquiterpenes from Laggera alata. J. Nat. Prod. 66: 1078-1081, 2003.

9. Wu Y.H., Li X.P., Zhou C.X., Chen H.Y., Zhao J. and Zhao Y., Antiinflammatory activity of total flavonoids from Laggera alata. Chin. Pharm. J. 2006. (in press).

10. Wenkert E. and Gottlieb H.E., Carbon-13 nuclear magnetic resonance spectroscopy of flavonoid and isoflavonoid compounds. Phytochemistry 16: 1811-1816, 1977.

11. Li S.L. and Ding J.K., The flavonols from Laggera pterodonta. Acta Botanica Yunnanica 16: 434-436, 1994.

12. Timmermann B.N., Mues R., Mabry T.J. and Powell A.M., 6-methoxyflavonoids from Brickellia laciniata (compositae). Phytochemistry 18: 1855-1858, 1979.

13. Rodriguez E., Carman N.J. and Mabry T.J., A general NMR procedure for locating methoxyl groups in all flavone and flavonol aglycones and some glycosides utilizing trimethylsilyl ethers and benzene-induced shifts. Phytochemistry 11: 409-410, 1972.

14. Valesi A.G., Rodriguez E., Velde G.V. and Mabry T.J., Methylated flavonols in Larrea cuneifolia. Phytochemistry 11: 2821-2826, 1972.

15. Rodríguez E., Carman N.J., Chavez P. and Mabry T.J., Quercetagetin 3,3'-dimethyl ether, a new flavonoid from Parthenium tomentosum. Phytochemistry 11: 1507-1508, 1972.

16. Anil Kumar P.R., Menon B., Anil Kumar T.V. and Kumari T.V., Culture of neonatal rat liver cells: a preliminary observation. Trends Biomaterials Artif. Organs. 16: 34-47, 2002.

17. Tapia A., Rodriguez J., Theoduloz C., Lopez S., Feresin G.E. and Schmeda-Hirschmann G., Free radical scavengers and antioxidants from Baccharis grisebachii. J. Ethnopharmacol. 95: 155-161, 2004.

18. Mousson B., Desjacques P. and Baltassat P., Measurement of xanthine oxidase activity in some human tissues. An optimized method. Enzyme 29: 32-43, 1983.

19. Clawson G.A., Mechanisms of carbon tetrachloride hepatotoxicity. Pathol. Immunopathol. Res. 8: 104-112, 1989.

20. Park E.J., Zhao Y.Z., Kim Y.C. and Sohn D.H., Protective effect of (S)-Bakuchiol from Psoralea corylifolia on rat liver injury in vitro and in vivo. Planta Medica 71: 508-513, 2005.
21. Zhu Y.Z., Huang S.H., Tan B.K.H., Sun J., Whiteman M. and Zhu Y.C., Antioxidants in chinese herbal medicines: a biochemical perspective. Nat. Prod. Rep. 21: 478-489, 2004.

22. Kiso Y., Tohkin M., Hikino H., Hattori M., Sakamoto T. and Namba T., Mechanism of antihepatotoxic activity of glycerrhizin. I. Effect of free radical generation and lipid peroxidation. Planta Medica 50: 298-302, 1984.

23. Middleton E.Jr., Kandaswami C. and Theoharides T.C., The effects of plant flavonoids on mammalian cells:Implications for inflammation, heart disease, and cancer. Pharmacol. Rev. 52: 673-751, 2000.

24. Torel J., Cillard J. and Cillard P., Antioxidant activity of flavonoids and reactivity with peroxy radical. Phytochemistry 25: 383-385, 1986.

25. Bohlmann F., Wallmeyer M., Jakupovic J., Gerke T., King R.M. and Robinson H., Cuauthemone sesquiterpenoids from Blumea alata. Phytochemistry 24: 505-509, 1985.

26. Li S.L. and Ding J.K., Three new sesquiterpenols from Laggera pterodonta. Acta Botanica Yunnanica 15: 303305, 1993.

27. Li S.L. and Ding J.K., The structure of pterodontetraol from Laggera pterodonta. Acta Botanica Yunnanica 16: 313-314, 1994.

28. Li S.L. and Ding J.K., Four new sesquiterpenoids from Laggera pterodonta. Acta Botanica Yunnanica 18: 349352, 1996.

29. Li S.L., Ding J.K., Jiang B. and Na B., Sesquiterpenoid glucosides from Laggera pterodonta. Phytochemistry 49: 2035-2036, 1998.

30. Wei J.X., Hu J.L. and Wang C.B., Studies on the chemical constitutents of the volatile oils from Laggera pterodonta (DC) Benth. Acad. J. Kunming Medical Coll. 13: 21-24, 1992.

31. Wei J.X., Zhao A.H., Hu J.L. and Zhu Y., Study on chemical constituents of Laggera pterodonta. Acad. J. Kunming Med. College 16: 83-84, 1995.

32. Zhao A.H. and Wei J.X., Studies on the constituent of decoctum of Laggera pterodonta DC) Benth II. Acta Chim. Sin. 52: 517-520, 1994.

33. Zhao A.H., Zhu Y. and Wei J.X., Chemical study on Laggera pterodonta. Chin. Pharm. J. 30: 264-265, 1995.

34. Raharivelomanana P., Bianchini J.P., Ramanoelina A.R.P., Rasoarhona J.R.E., Faure R. and Cambon A., Eudesmane sesquiterpenes from Laggera alata. Phytochemistry 47: 1085-1088, 1998.

35. Lee E.S., Lee H.E., Shin J.Y., Yoon S. and Moon J.O., The flavonoid quercetin inhibits dimethylnitrosamine-induced liver damage in rats. J. Pharm. Pharmacol. 55: 1169-1174, 2003.

36. Matsuda H., Murakami T., Kageura T., Ninomiya K., Toguchida I., Nishida N. and Yoshikawa M., Hepatoprotective and nitric oxide production inhibitory activities of coumarin and polyacetylene constituents from the roots of Angelica furcijuga. Bioorg. Med. Chem. Lett. 8: 2191-2196, 1998.

37. Oh H., Ko E.K., Jun J.Y., Oh M.H., Park S.U., Kang K.H., Lee H.S. and Kim Y.C., Hepatoprotective and free radical scavenging activities of prenylflavonoids, coumarin, and stilbene from Morus alba. Planta Med. 68: 932-934, 2002.

38. Adzet T., Camarasa J. and Laguna J.C., Hepatoprotective activity of polyphenolic compounds from Cynara scolymus 
against CCl4 toxicity in isolated rat hepatocytes. J. Nat. Prod. 50: 612-617, 1987.

39. Banskota A.H., Tezuka Y., Adnyana I.K., Xiong Q., Hase K., Tran K.Q., Tanaka K., Saiki I. and Kadota S., Hepatoprotective effect of Combretum quadrangulare and its constituents. Biol. Pharm. Bull. 23: 456-460, 2000.
40. Gilani A.H., Janbaz K.H. and Shah B.H., Quercetin exhibits hepatoprotective activity in rats. Biochem. Soc. Trans. 25: 619, 1997. 